\title{
Chế độ hợp tác quốc tế trong Tố tụng Hình sự Trung Quốc
}

\author{
Ngũ Quang Hồng* \\ Đại học Dân tộc Quảng Tây, 188 Đông Đại học, Nam Ninh, Quảng Tây, Trung Quốc \\ Nhận ngày 16 tháng 11 năm 2017 \\ Chỉnh sửa ngày 30 tháng 11 năm 2017; Chấp nhận đăng ngày 28 tháng 12 năm 2017
}

\begin{abstract}
Tóm tắt: Hợp tác quốc tế trong Tố tụng hình sự được pháp luật Trung Quốc qui định từ khá sớm. Những qui định về hợp tác quốc tế trong Tố tụng hình sự đã góp phần tích cực vào việc đấu tranh, xử lý tội phạm có yếu tố nước ngoài, tội phạm có tổ chức, tội phạm xuyên quốc gia... và thúc đẩy quan hệ hợp tác quốc tế sâu rộng của Trung Quốc với các quốc gia khác trong lĩnh vực Tư pháp Hình sự. Bài viết này sẽ giới thiệu một số nội dung cơ bản về hợp tác quốc tế trong tố tụng hình sự của Trung quốc và những vấn đề đặt ra.
\end{abstract}

Tư khóa: Cộng hòa Nhân dân Trung Hoa, Tố tụng Hình sự, hợp tác quốc tế trong Tố tụng Hình sự, dẫn độ, tương trợ tư pháp, chuyển giao người phạm tội.

\section{Khái niệm, ý nghĩa của hợp tác quốc tế trong Tố tụng Hình sự Trung Quốc}

Điều 17 của Luật tố tụng hình sự Trung Quốc quy định: "Căn cứ theo các điều ước quốc tế mà nước Cộng hòa Nhân dân Trung Hoa ký kết hoặc tham gia; hoặc căn cứ theo các nguyên tắc ưu đãi lẫn nhau, các cơ quan tư pháp Trung Quốc và các cơ quan tư pháp nước ngoài có thể đề nghị hợp tác quốc tế trong tố tụng hình sự", Căn cứ theo điều này, cái gọi là hợp tác quốc tế trong tố tụng hình sự, chính là chỉ sự hợp tác giữa cơ quan tư pháp Trung Quốc và cơ quan tư pháp nước ngoài. Căn cứ theo các điều ước quốc tế mà Trung Quốc ký kết hoặc tham gia, hoặc căn cứ theo các nguyên tắc ưu đãi lẫn nhau, hợp tác hỗ trợ lẫn nhau, giúp đỡ nhau

\footnotetext{
${ }^{*}$ ĐT.: 86-613878110865.

Email: woods118@163.com

https://doi.org/10.25073/2588-1167/vnuls.4126

${ }^{1}$ 中华人民共和国刑事诉讼法[2012年修正].
}

thực thi một chế độ của một số hành vi tố tụng hình sự.

Thiết lập và thực thi chế độ hợp tác quốc tế trong tố tụng hình sự, có những ý nghĩa vô cùng quan trọng như sau:

Đầu tiên, có lợi trong việc bảo vệ chủ quyền và quyền lợi của quốc gia. Hỗ trợ tư pháp là một loại hành vi mang tính hỗ trợ giữa các cơ quan tư pháp của các nước khác nhau. Đối với cơ quan tư pháp của một nước, nó có ý nghĩa là thỉnh cầu cơ quan tư pháp nước ngoài thực hiện nghĩa vụ hợp tác, cũng có nghĩa là có quyền lợi thỉnh cầu cơ quan tư pháp nước ngoài giúp sức hỗ trợ. Bởi vậy, thực hiện chế độ này trong tố tụng hình sự của Trung Quốc, một khi có phát sinh vấn đề tội phạm của Trung Quốc và của công dân Trung Quốc mà cần có sự hỗ trợ hợp tác của cơ quan tư pháp nước ngoài, thì có thể thông qua con đường này để chứng thực việc phạm tội và trừng phạt kẻ phạm tội, có hiệu quả trong việc bảo vệ chủ quyền quốc gia, bảo vệ lợi ích của quốc gia và của công dân. 
Thư hai, có lợi trong tăng cường việc hợp tác trong tố tụng hình sự giữa Trung Quốc và nước ngoài, trừng trị những kẻ phạm tội mang tính quốc tế. Việc tồn tại những loại hình tội phạm mang tính quốc tế như kẻ cướp, kẻ trộm, tội phạm ma túy,... là một tiền đề khách quan vô cùng quan trọng của việc phát sinh và phát triển việc hợp tác quốc tế trong tố tụng hình sự; Trừng phạt tội phạm mang tính quốc tế là một nhiệm vụ quan trong trong hợp tác quốc tế trong tố tụng hình sự. Tội phạm mang tính quốc tế luôn luôn là các vụ án xuyên quốc gia, đồng thời nguy hại đến cơ số quốc gia thậm chí là lợi ích của rất nhiều quốc gia. Tất nhiên điều này cho dù bất kỳ quốc gia nào đi nữa chỉ dựa vào lực lượng tư pháp của nước mình cũng đều không thể đủ khả năng xử lý một cách có hiệu quả được. Thực thi chế độ hợp tác trong tố tụng hình sự, cơ quan tư pháp Trung Quốc sẽ được hợp tác với cơ quan tư pháp của các quốc gia khác, cùng nhau sử dụng các biện pháp dự phòng có hiệu quả và trừng trị những loại tội phạm này, từ đó mà bảo vệ được lợi ích chung của toàn nhân loại, có những cống hiến cần có cho sự hòa bình và phát triển của thế giới.

\section{Chủ thể hợp tác quốc tế trong Tố tụng Hình sự Trung Quốc}

Căn cứ theo quy định tại Điều 17 luật tố tụng hình sự Trung Quốc, chủ thể của hợp tác quốc tế trong tố tụng hình sự là cơ quan tư pháp của Trung Quốc và cơ quan tư pháp nước ngoài. Thông thường có thể nói, cơ quan tư pháp của Trung Quốc chính là chỉ tòa nhán dân dân và viện kiểm sát nhân dân, cơ quan tư pháp nước ngoài chỉ là chỉ tòa án. Nhưng căn cứ theo đặc điểm mang tính tương trợ của hợp tác hỗ trợ tư pháp và tình hình thực tế của hợp tác quốc tế trong tố tụng hình sự mà Trung Quốc triển khai, thì chủ thể của hợp tác quốc tế trong tố tụng hình sự phải bao gồm:

(1) Tòa án nhân dân Trung Quốc và tòa án nước ngoài. Không phải nghi ngờ, tòa án nhân dân Trung Quốc và tòa án nước ngoài đều là cơ quan tư pháp quốc gia được các nước công nhận, bởi vậy lẽ đương nhiên là chủ thể của hợp tác quốc tế trong tố tụng hình sự.

(2) Viện kiểm sát nhân dân Trung Quốc và cơ quan kiểm sát nước ngoài. Ở Trung Quốc, viện kiểm sát nhân dân cũng chính là cơ quan tư pháp quốc gia, căn cứ theo thỉnh cầu mang tính tương trợ của hợp tác tư pháp, viện kiểm sát nhân dân Trung Quốc chỉ có thể thỉnh cầu hợp tác quốc tế trong tố tụng hình sự với cơ quan kiểm sát nước ngoài. Bởi vậy, viện kiểm sát Trung Quốc và cơ quan kiểm sát nước ngoài cũng có thể được coi là chủ thể của hợp tác quốc tế trong tố tụng hình sự.

(3) Cơ quan công an Trung Quốc và cơ quan cảnh sát nước ngoài. Thường người ta cho rằng, cơ quan công an Trung Quốc không phải là cơ quan tư pháp, nhưng lâu nay, cơ quan công an Trung Quốc và cơ quan cảnh sát nước ngoài tiến hành không ít các công việc hợp tác quốc tế trong lĩnh vực tố tụng hình sự và hợp tác trong các công vụ của ngành cảnh sát. Mà việc yêu cầu hai bên hỗ trợ lẫn nhau trong việc hợp tác quốc tế trong tố tụng hình sự đúng là cũng mang tính cần thiết. Có người cho rằng, sự hợp tác quốc tế giữa cơ quan công an Trung Quốc và cơ quan cảnh sát nước ngoài, có thể thông qua các tổ chức cảnh sát hình sự quốc tế để tiến hành giải quyết, nhưng trên thực tế việc thông qua các tổ chức cảnh sát hình sự quốc tế chủ yếu là để truy nã các nghi phạm phạm tội hoặc bị cáo chạy ra nước ngoài, mà công việc hỗ trợ tư pháp thì lại do hai bên trực tiếp tiến hành. Đối với vấn đề này, phần "quy định" Bộ Công an Trung Quốc đã quy định rất rõ ràng. Bởi vậy, giải thích nghĩa rộng của "cơ quan tư pháp Trung Quốc và cơ quan tư pháp nước ngoài " trong quy định tại Điều 17 luật tố tụng hình sự Trung Quốc", tức là đã bao gồm cơ quan công an Trung Quốc và cơ quan cảnh sát nước ngoài.

Để bảo đảm tính thống nhất và tính nghiêm túc trong việc hợp tác quốc tế trong tố tụng hình sự, bảo vệ chủ quyền tư pháp quốc gia, việc yêu cầu hợp tác tư pháp giữa cơ quan tư pháp Trung Quốc và cơ quan tư pháp nước ngoài phải do cơ quan tư pháp tối cao của hai nước liên hệ với nhau. Ví dụ: Trong “điều ước hợp tác quốc tế 
trong tố tụng dân sự và hình sự giữa nước Cộng hòa Nhân dân Trung Hoa và Ukraine" có chỉ định các cơ quan ngang nhau của mỗi nước như: Bộ tư pháp mỗi nước và các cơ quan thẩm phán tối cao, các cơ quan kiểm sát tối cao được phép liên hệ với nhau. Như vậy đã xác định rõ, cơ quan hành chính tư pháp không có chức năng tố tụng hình sự, do đó cũng không thể chấp hành các công việc hợp tác quốc tế trong tố tụng hình sự một cách cụ thể. Nhưng do tính tiện lợi trong việc cơ quan chính phủ liên hệ với bên đối ngoại, bởi vậy mà rất nhiều quốc gia đã chỉ định Bộ tư pháp của họ là cơ quan liên hệ hợp tác hỗ trợ tư pháp, quy định các cơ quan này là đơn vị thống nhất phụ trách việc chuyển giao liên hệ thỉnh cầu hỗ trợ tư pháp và thực hiện các kết quả.

\section{Căn cứ hợp tác quốc tế trong Tố tụng Hình sự Trung Quốc}

Cơ quan tư pháp Trung Quốc và cơ quan tư pháp nước ngoài có các yêu cầu hỗ trợ lẫn nhau trong hợp tác tác tư pháp trong tố tụng hình sự, cần phải có các căn cứ rõ ràng chính xác, nếu không thì sẽ không được thực thi. Căn cứ theo quy định tại Điều 17 luật tố tụng hình sự Trung Quốc, các căn cứ ấy được quy thành hai loại sau[1]:

(1) Các điều ước quốc tế mà Trung Quốc ký kết hoặc tham gia

Từ năm 1987 trở lại đây, Trung Quốc đã ký kết các điều ước hợp tác quốc tế về hình sự, dân sự và tố tụng hình sự hoặc các hiệp định có các nội dung về hợp tác quốc tế trong tố tụng hình sự với hơn 20 quốc gia như: Ba Lan, Mông Cổ, Romania, Bulgaria, Nga, Hy Lạp, Canada, Thổ Nhĩ Kỳ, Việt Nam, Hàn Quốc, ... Đồng thời cũng ký kết các thỏa ước dẫn độ tội phạm với hơn 10 nước như: Thái Lan, Nga, Belarus, Romania, Bulgaria, Kazakhstan, Mông Cổ, Ukraine... Đồng thời, Trung Quốc còn tham gia các "công ước thống nhất về danh mục các chất ma túy", "công ước Hague", "công ước Montreal", "công ước về các chất hướng thần", "công ước chống buôn bán bất hợp pháp các loại chất ma túy và chất hướng thần”, “công ước chống tội phạm xuyên quốc gia" của Liên hợp quốc và "Công ước phòng chống tham nhũng" của Liên hợp quốc... Các công ước này đều quy định, đối với các tội phạm quốc tế, nước tham gia ký kết công ước, khi đưa ra tố tụng hình sự đối với tội phạm, phải cung cấp sự hợp tác tư pháp lẫn nhau ở giới hạn cao nhất, bao gồm cung cấp các chứng cứ... Các điều ước quốc tế Trung Quốc đã ký kết và tham gia, thì đều sẽ là do cơ quan tư pháp tiến hành cung cấp các căn cứ pháp luật hỗ trợ tư pháp.

(2) Nguyên tắc ưu đãi lẫn nhau

Bình đẳng cùng có lợi là một nguyên tắc cơ bản trong luật quốc tế hiện đại, với lĩnh vực hoạt động tư pháp nó cũng thích hợp như nhau. Bởi vậy, trong trường hợp Trung Quốc và một quốc gia nào đó không ký kết các điều ước hợp tác hỗ trợ tư pháp hoặc hai nước không cùng tham gia một công ước quốc tế có các điều khoản về hợp tác hỗ trợ tư pháp, nếu cơ quan tư pháp nước này căn cứ theo thỉnh cầu của cơ quan tư pháp Trung Quốc cung cấp các hỗ trợ tư pháp, thì cơ quan tư pháp Trung Quốc cũng phải có các hỗ trợ tư pháp theo các thỉnh cầu của cơ quan tư pháp nước ấy. Làm như vậy, có lợi trong việc phát triển quan hệ hợp tác hữu nghị giữa Trung Quốc và nước ngoài trên cơ sở bình đẳng, cũng có lợi trong việc tiến hành thuận lợi các hoạt động tố tụng hình sự có yếu tố nước ngoài và xử lý chính xác các vụ án hình sự có yếu tố nước ngoài của Trung Quốc. Bởi vậy, nguyên tắc ưu đãi lẫn nhau cũng là căn cứ quan trọng để cơ quan tư pháp Trung Quốc tiến hành các công việc hợp tác quốc tế trong tố tụng hình sự.

\section{Nội dung hợp tác quốc tế trong Tố tụng Hình sự Trung Quốc}

Hợp tác hỗ trợ tư pháp, có thể chia thành hai phương diện, một là cơ quan tư pháp Trung Quốc thỉnh cầu cơ quan tư pháp nước ngoài cung cấp các hợp tác quốc tế trong tố tụng hình sự, hai là cơ quan tư pháp nước ngoài thỉnh cầu cơ quan tư pháp Trung Quốc cung cấp các hợp 
tác quốc tế trong tố tụng hình sự. Nhưng cho dù là ở phương diện nào, nội dung của nó đều là tương đồng. Căn cứ theo các quy định trong điều ước quốc tế mà Trung Quốc ký kết và tham gia, hợp tác quốc tế trong tố tụng hình sự chủ yếu có 6 nội dung sau:

(1) Điều tra lấy chứng cứ. Bao gồm làm thay việc thẩm vấn các đương sự, truy vấn người làm chứng, người bị hại, người giám định; tiến hành giám định, khám nghiệm, kiểm tra, khám xét lục soát, kiểm tra niêm phong, giam giữ, nhận dạng...

(2) Tống đạt văn thư. Bao gồm làm thay việc tống đạt văn thư tố tụng và văn thư ngoài tố tụng. Trong đó, văn thư tố tụng là các loại tài liệu và văn thư pháp luật được cơ quan tư pháp lập ra trong quá trình tố tụng hình sự, như bản phán quyết, bản xét định, quyết định, giấy triệu tập, thông báo hầu tòa... Các văn thư ngoài tố tụng là các văn thư hoặc các tài liệu văn tự ngoài các văn thư tố tụng, nhưng có liên quan đển trình tự tố tụng hình sự, như chứng minh thư, công hàm gửi đi và phúc đáp...

(3) Chuyển giao chứng cứ. Bao gồm việc chuyển giao các tài liệu chứng cứ như vật chứng, văn thư làm chứng, tài liệu nghe nhìn, các dữ liệu điện tử và các tang vật, các khoản tiền phạm pháp.

(4) Thông báo kết quả tố tụng. Bao gồm thông báo các nội dung lập hồ sơ chuyên án, điều tra, sử dụng các biện pháp cưỡng chế, khởi tố hoặc không khởi tố, phán quyết hoặc xét định.

(5) Dẫn độ. Là việc một nước đưa kẻ đang có mặt trên lãnh thổ nước này nhưng bị một nước khác kết án phạm tội hoặc phán quyết xử lý hình sự chuyển giao cho nước đó xét xử hoặc chấp hành thi hành án. Suy xét đến việc dẫn độ có tính đặc trưng không giống nhau trong hình thức hỗ trợ tư pháp khác, cho nên rất nhiều quốc gia đều lập riêng các quy định chuyên về việc dẫn độ. Đồng thời thông qua việc ký kết thỏa thuận dẫn độ để giải quyết vấn đề này. "Luật dẫn độ" của Trung Quốc cũng có các quy định cụ thể, rõ ràng, chính xác về việc dẫn độ giữa Trung Quốc và nước ngoài.
(6) Giao lưu và hợp tác về thông tin tình báo tội phạm.

\section{Trình tự hợp tác quốc tế trong Tố tụng Hình sự Trung Quốc}

(1) Trình tự cơ quan tư pháp Trung Quốc thỉnh cầu cơ quan tư pháp nước ngoài hợp tác quốc tế trong tố tụng hình sự.

Cơ quan tư pháp Trung Quốc khi cần thỉnh cầu cơ quan tư pháp nước ngoài hỗ trợ tư pháp, phải căn cứ theo các quy định trong các điều ước quốc tế có liên quan đưa ra thư thỉnh cầu hỗ trợ tư pháp và các tài liệu đi kèm, văn bản dịch tương ứng. Sau khi cơ quan tư pháp cấp tỉnh thẩm duyệt xong, chuyển lên cơ quan tư pháp tối cao. Căn cứ theo quy định tại điều số 5 "Điều ước mô phạm hỗ trợ các vụ án hình sự" được đại hội Liên hợp quốc thông qua năm 1990, thư thỉnh cầu phối hợp giúp đỡ tư pháp phải bao hàm những nội dung sau: (1) Tên của tổ chức thỉnh cầu và tên của cơ quan chủ quản tiến hành điều tra hoặc tố tụng của thỉnh cầu này; (2) Mục đích của việc thỉnh cầu và giải thích ngắn gọn việc cần sự phối hợp giúp đỡ; (3) Ngoài trường hợp yêu cầu gửi phát văn kiện, phải thuật lại sự thực chứng cứ cấu thành tội danh và các giải thích và văn bản pháp luật có liên quan; (4) Phải có họ tên và địa chỉ người nhận; (5) Nước thỉnh cầu hi vọng bất kỳ trình tự đặc biệt nào hoặc các lý do, tình tiết yêu cầu được tuân thủ, bao gồm giải thích có phải yêu cầu được tuyên thề hoặc kiểm tra tính trung thực của các chứng cứ hoặc lời làm chứng không; (6) Giải thích đối với các thỉnh cầu hy vọng được chấp hành trong một kỳ hạn nhất định có liên quan; (7) Chấp hành thỏa đáng các thỉnh cầu đối với các tài liệu quan trọng khác. Căn cứ theo "Điều ước mô phạm hỗ trợ các vụ án hình sự" và các quy định của các điều ước quốc tế có liên quan, cơ quan tư pháp Trung Quốc trong khi thỉnh cầu cơ quan tư pháp nước ngoài tiến hành hợp tác hỗ trợ tư pháp, thư thỉnh cầu và các văn bản đính kèm phải sử dụng chữ viết của Trung Quốc, đồng thời đính kèm thêm bản dịch ra ngôn ngữ của nước được thỉnh 
cầu hoặc bản dịch ra một ngôn ngữ bất kỳ mà nước được thỉnh cầu có thể chấp nhận.

Sau khi cơ quan tư pháp tối cao nhận được thư đề nghị và các tài liệu của cơ quan tư pháp các cấp địa phương yêu cầu cơ quan tư pháp nước ngoài cung cấp hỗ trợ, cần phải căn cứ vào các hiệp ước để tiến hành thẩm tra. Đối với những trường hợp phù hợp với các quy định có liên quan trong hiệp ước, có đầy đủ các tài liệu, cần phải chuyển cho cơ quan trung ương nước ngoài có kí hiệp ước các tài liệu nói trên, hoặc giao cho cơ quan Trung ương nhà nước khác (như bộ Tư pháp, bộ Ngoại giao) xử lí. Đối với các trường hợp không phù hợp với các quy định trong hiệp ước hoặc tài liệu không đầy đủ, cần phải trả lại cho các cơ quan tư pháp yêu cầu hỗ trợ để bổ sung hoặc chỉnh sửa. Sau khi cơ quan tư pháp nước ngoài tiến hành hỗ trợ và chuyển kết quả thi hành tới cơ quan tư pháp tối cao quốc gia, cơ quan tư pháp tối cao cần phải chuyển ngay cho cơ quan tư pháp các cấp yêu cầu hỗ trợ.

Căn cứ theo quy định tại điều số 371 của "quy định" Bộ Công an Trung Quốc, các nghi phạm, bị cáo hoặc tội phạm cần phải thông qua tổ chức cảnh sát hình sự quốc tế truy nã hoặc các tài liệu cần truy vấn, các vấn đề cần điều tra thu thập chứng cứ cần nhờ đến sự hỗ trợ của cảnh sát hình sự quốc tế, phải trình đơn lên Cục Trung tâm quốc gia Trung Quốc trình báo tổ chức cảnh sát hình sự quốc tế.

Cơ quan tư pháp Trung Quốc thỉnh cầu cơ quan tư pháp nước ngoài hợp tác hỗ trợ tư pháp, căn cứ theo quy định điều ước, phải chi trả các vấn đề về kinh phí, sau khi cơ quan tư pháp tối cao nhận được các hóa đơn chứng từ thu phí của bên nước được thỉnh cầu, phải ngay lập tức chuyển giao cho cơ quan tư pháp có liên quan để thanh toán.

(2) Trình tự cơ quan tư pháp nước ngoài thỉnh cầu cơ quan tư pháp Trung Quốc hợp tác trong lĩnh vực tố tụng hình sự.

Cơ quan tư pháp tối cao của Trung Quốc phải thông qua con đường liên lạc được quy định trong các điều ước quốc tế có liên quan hoặc con đường ngoại giao, để tiếp nhận các thỉnh cầu hỗ trợ tư pháp được cơ quan tư pháp nước ngoài hoặc cơ quan ngoại giao nước ngoài đưa ra. Thư thỉnh cầu này (nội dung như trên) và các văn bản đính kèm phải kèm thêm bản dịch tiếng Trung hoặc bản dịch sang các chữ viết khác được quy định trong các điều lệ quốc tế.

Sau khi cơ quan tư pháp tối cao nhận được thỉnh cầu hỗ trợ tư pháp do một bên nước ngoài đưa ra, phải căn cứ theo pháp luật Trung Quốc và các điều ước hỗ trợ tư pháp có liên quan để tiến hành thẩm tra. Nhằm bảo vệ chủ quyền quốc gia, điều ước hợp tác quốc tế trong lĩnh vực hình sự được ký kết giữa hai nước đều có các quy định đối với việc tạo điều kiện hỗ trợ hoặc từ chối cung cấp các hỗ trợ, Trung Quốc cũng không ngoại lệ.

Ví dụ: Trong "hiệp định về hợp tác quốc tế trong lĩnh vực dân sự và hình sự" được Trung Quốc và Ba Lan ký kết có quy định, thuộc một trong các tình huống sau đây, một trong hai bên có thể từ chối hợp tác quốc tế trong lĩnh vực hình sự: (1) Nếu một bên ký kết được thỉnh cầu cho rằng tội phạm được đề cập đến trong việc thỉnh cầu này mang tính chất chính trị hoặc quân sự; (2) Căn cứ theo pháp luật của bên ký kết được thỉnh cầu, hành vi được đề cập đến trong thỉnh cầu không cấu thành tội; (3) Nghi phạm hoặc tội phạm được đề cập đến trong thỉnh cầu này là công dân của một bên tham gia ký kết được thỉnh cầu, mà lại không ở trong lãnh thổ của bên tham gia ký kết. Ngoài ra, theo điều ước quốc tế liên quan, nếu bên được thỉnh cầu cho rằng thực hiện hỗ trợ có thể gây phương hại đến chủ quyền, an toàn hoặc trật tự công cộng, cũng có thể từ chối hỗ trợ tư pháp. Qua thẩm tra, đối với thư thỉnh cầu phù hợp với các qui định của điều ước và đầy đủ hồ sơ đi kèm, cơ quan tư pháp tối cao cần giao cho cơ quan tư pháp cấp tỉnh liên quan thực hiện hoặc chỉ định cơ quan tư pháp liên quan thực hiện, hoặc giao cho cơ quan liên quan khác do cơ quan có thẩm quyền của Trung ương chỉ định thực hiện. Đối với thư thỉnh cầu không phù hợp điều ước hoặc các quy định pháp luật liên quan, cần gửi trả lại bên thỉnh cầu theo con đường tiếp nhận thỉnh cầu, không được thực hiện; Đối 
với thư thỉnh cầu không đầy đủ hồ sơ đi kèm, cần yêu cầu bên thỉnh cầu tiến hành bổ sung.

Sau khi nhận được thư thỉnh cầu hỗ trợ tư pháp và hồ sơ đi kèm do cơ quan tư pháp tối cao chuyển giao, cơ quan tư pháp cấp tỉnh liên quan có thể thực hiện trực tiếp, cũng có thể chì định cơ quan tư pháp liên quan thực hiện. Sau khi nhận được thư thỉnh cầu hỗ trợ tư pháp và hồ sơ đi kèm, co quan tư pháp chịu trách nhiệm thực hiện cần thực hiện kịp thời và gửi báo cáo kết quả thực hiện và hồ sơ liên quan lên cơ quan tư pháp tối cao thông qua cơ quan tư pháp cấp tỉnh theo mẫu và ngôn ngữ điều ước quy định; Đối với các thư thỉnh cầu không thể thực hiện (ví dụ người bị tình nghi phạm tội tử vong v.v...), cần gửi thư thỉnh cầu hỗ trợ tư pháp và hồ sơ liên quan cùng lý do không thể thực hiện báo cáo lên cơ quan tư pháp tối cao thông qua cơ quan tư pháp cấp tỉnh. Vì địa chỉ thư thỉnh cầu cung cấp không rõ, thông tin không chính xác, hồ sơ không đầy đủ khó có thể thực hiện thỉnh cầu này, phải thông qua cơ quan tư pháp tối cao yêu cầu bên thỉnh cầu bổ sung hồ sơ ngay.

Cơ quan tư pháp tối cao phải tiến hành thẩm tra kết quả thực hiện. Nếu phù hợp yêu cầu của bên thỉnh cầu và các quy định liên quan thì cơ quan tư pháp tối cao chuyển cho bên thỉnh cầu. Cơ quan tư pháp Trung Quốc hỗ trợ tư pháp, nếu thư thỉnh cầu có đưa ra thời hạn thực hiện thì cần hoàn thành theo thời hạn; Nếu không đưa thời hạn thực hiện, thông thường việc điều tra lấy chứng cứ được hoàn thành trong vòng 3 tháng. Đối với việc gửi hồ sơ tố tụng hình sự, bộ công an quy định hoàn thành trong vòng 10 ngày, viện kiểm sát nhân dân tối cao quy định thông thường cần hoàn thành trong vòng 20 ngày. Trường hợp không thể thực hiện theo thời hạn, phải nêu rõ tình hình và lý do, trình báo lên co quan tư pháp tối cao để báo cho bên thỉnh cầu.

Cơ quan tư pháp Trung Quốc hỗ trợ tư pháp hình sự, theo quy định của Điều ước quốc tế liên quan nếu cần thu phí bên thỉnh cầu thì phải gửi báo chi phí và hóa đơn cùng kết quả thực hiện hỗ trợ tư pháp lên cơ quan tư pháp tối cao để chuyển giao cho bên thỉnh cầu. Sau khi nhận được các chi phí trên, cơ quant ư pháp tối cao phải chuyển giao ngay cho cơ quan tư pháp liên quan ngay.

(3) Quy trình dẫn độ theo quy định của "Luật dẫn độ"”[2] Trung Quốc

Thứ nhất, điều kiện và quy trình nước ngoài yêu cầu Trung Quốc dẫn độ

Theo quy định của "Luật dẫn độ", nước ngoài khi thỉnh cầu Trung Quốc dẫn độ bắt buộc đáp ứng đồng thời hai điều kiện sau mới được phép dẫn độ: (1) Hành vi nêu trong thỉnh cầu dẫn độ đều không cấu thành tội phạm theo luật pháp Trung Quốc và luât pháp nước thỉnh cầu; (2) Đối với thỉnh cầu dẫn độ để thực hiện tố tụng hình sự, theo luật Trung Quốc và luật pháp nước thỉnh cầu, tội phạm nêu ra trong thỉnh cầu dẫn độ đều không được kết án tù 1 năm trở lên hoặc hình phạt nặng hơn; Đối với thỉnh cầu dẫn độ để thực hiện hình phạt, khi đưa ra thỉnh cầu dẫn độ, thời hạn phạt tù của người bị thỉnh cầu dẫn độ chưa hoàn thành tối thiểu còn 6 tháng.

Thỉnh cầu dẫn độ của nước ngoài đối với Trung Quốc nếu có một trong các trường hợp sau phải từ chối dẫn độ: (1) Theo luật pháp Trung Quốc, người bị thỉnh cầu dẫn độ có quốc tịch Nước cộng hòa nhân dân Trung Hoa; (2) Khi nhận được thỉnh cầu dẫn độ, cơ quan tư pháp Trung Quốc đã kết án có hiệu lực đối với tội phạm nêu ra trong thỉnh cầu dẫn độ, hoặc đã kết thúc trình tự tố tụng hình sự; (3) Thỉnh cầu dẫn độ do phạm tội chính trị hoặc Trung Quốc đã cho người bị thỉnh cầu dẫn độ được hưởng quyền bảo vệ; (4) Người bị thỉnh cầu dẫn độ có thể bị tố tụng hình sự hoặc thực hiện hình phạt vì các lý do như chủng tộc, tôn giáo, quốc tịch, giới tính, bất đồng chính trị hoặc thân phận v.v..., hoặc người bị thỉnh cầu dẫn độ không được đãi ngộ công bằng vì các lý do trên trong quá trình tư pháp; (5) Theo luật pháp Trung Quốc hoặc nước thỉnh cầu, phạm tôi nêu ra trong thỉnh cầu dẫn độ hoàn toàn là phạm tôi quân sự; (6) Theo luật pháp Trung Quốc hoặc nước bị thỉnh cầu, khi nhận được thỉnh cầu dẫn độ, vì phạm tội đã quá thời hạn truy tố hoặc người bị thỉnh cầu dẫn độ được ân xá, không 
được truy cứu trách nhiệm hình sự đối với người bị thỉnh cầu dẫn độ; (7) Người bị thỉnh cầu dẫn độ đã từng bị hoặc có thể bị tra tấn hoặc bị ngược đãi tàn nhẫn, vô nhân đạo hoặc xúc phạm nhân cách hoặc bị phạt tại nước thỉnh cầu; (8) Nước thỉnh cầu đưa ra thỉnh cầu dẫn độ theo phán quyết vắng mặt nhưng trừ trường hợp nước thỉnh cầu cam kết sau khi dẫn độ sẽ dành cơ hội cho người bị thỉnh cầu dẫn độ được phán quyết lại trong phiên toàn khác.

Thỉnh cầu dẫn độ của nước ngoài đối với Trung Quốc nếu có một trong các trường hợp sau có thể từ chối dẫn độ: (1) Trung Quốc có quyền quản lý hình sự đối với tội phạm nêu ra trong thỉnh cầu dẫn độ, và đang tiến hành tố tụng hình sự hoặc chuẩn bị thực hiện tố tụng hình sự đối với người bị thỉnh cầu dẫn độ; (2) Không được dẫn độ vì các lý do tuổi tác, sức khỏe của người bị thỉnh cầu dẫn độ để phù hợp với nguyên tắc nhân đạo.

Nước thỉnh cầu cần xin thỉnh cầu dẫn độ của Bộ ngoại giao Trung Quốc, và có "Đơn thỉnh cầu dẫn độ". "Đơn thỉnh cầu dẫn độ" cần ghi rõ các nội dung sau: (1) Tên cơ quan thỉnh cầu; (2) Họ tên, giới tính, tuổi, quốc tịch, loại và số giấy tờ tùy thân, nghề nghiệp, đặc điểm bên ngoài, nơi ở, nơi cư trú và các thông tin hỗ trọ nhận dạng thân phận hoặc để tìm người bị thỉnh cầu dẫn độ; (3) Vụ việc phạm tội, bao gồm thời gian, địa điểm, hành vi, kết quả phạm tội v.v...; (4) Các quy định phá luật về thời hạn truy tố và khung hình phạt.

Khi thỉnh cầu dẫn độ, nước thỉnh cầu phải cung cấp các tài liệu sau đồng thời với "Đơn thỉnh cầu dẫn độ": (1) Khi thỉnh cầu dẫn độ để thực hiện tố tụng hình sự, phải kèm theo lệnh truy nã hoặc bản sao các văn bản có giá trị tương đương khác; Khi thỉnh cần dẫn độ để thực hiện hình phạt thì phải kèm theo văn bản phán quyết đã có hiệu lực hoặc bản sao bản tuyên án, đối với tội phạm đã thực hiện một phần hình phạt, còn phải kèm theo giấy chứng nhận đã thực hiện hạn tù; (2) Chứng từ phạm tội hoặc tài liệu chứng cứ bắt buộc. Ngoài ra, nước thỉnh cầu nắm rõ ảnh, dấu vân tay của người bị thỉnh cầu dẫn độ và các tài liệu khác có thể cung cấp để xác nhận người bị thỉnh cầu dẫn độ cũng cần cung cấp. Đơn thỉnh cầu dẫn độ hoặc các hồ sơ liên quan khác của nước thỉnh cầu nộp phải do cơ quan quản lý của nước thỉnh cầu ký hoặc đóng dấu chính thức, và kèm theo bản dịch tiếng Trung hoặc bản dịch bằng ngôn ngữ khác được Bộ ngoại giao Trung Quốc chấp thuận áp dụng.

Khi thỉnh cầu dẫn độ, nước thỉnh cầu cần thực hiện các bảo đảm sau: (1) Nước thỉnh cầu không truy cứu trách nhiệm hình sự đối với tội phạm khác chưa bị dẫn độ trước khi thực hiện dẫn độ đối với người bị thỉnh cầu dẫn độ, cũng không được dẫn độ người này cho nước thứ ba. Nhưng trừ trường hợp được Trung Quốc đồng ý, trong vòng 30 ngày kể từ ngày kết thúc tố tụng tội dẫn độ, mãn hạn phạt tù hoặc trước ngày được thả người bị dẫn độ chưa rời khỏi nước thỉnh cầu, hoặc sau khi rời khỏi lại tự nguyện quay về. (2) Sau khi đưa ra thỉnh cầu, nước thỉnh cầu lại rút, hủy bỏ thỉnh cầu dẫn độ hoặc thỉnh cầu dẫn độ đưa ra sai sót, hoặc do nước thỉnh cầu chịu trách nhiệm đối với các tổn hại gây ra do người bị thỉnh cầu dấn độ khi thỉnh cầu. Trong trường hợp không có điều ước dẫn độ, nước thỉnh cầu cần đưa ra cam kết có đi có lại.

Sau khi nhận được thỉnh cầu cẫn độ của nước thỉnh cầu đưa ra, bộ ngoại giao Trung Quốc cần tiến hành thẩm tra "Đơn thỉnh cầu dẫn độ" và hồ sơ tài liệu đi kèm xem có phù hợp với các cuy định của "Luật dẫn độ" và Điều ước dẫn độ hay không. Sau khi thẩm tra, nếu cho rằng không phù hợp với quy định của "Luật dẫn độ" và Điều ước dẫn độ, có thể yêu cầu nước thỉnh cầu bổ sung hồ sơ trong vòng 30 ngày. Nếu nước thỉnh cầu yêu cầu, thời hạn nêu trên có thể kéo dài 15 ngày. Trường hợp nước thỉnh cầu không bổ sung hồ sơ trong thời hạn nêu trên, bộ ngoại giao cần chấm dứt vụ án dẫn độ này, nước thỉnh cầu có thể thỉnh cầu dẫn độ người này một lần nữa với cùng một phạm tội; Nếu cho rằng phù hợp với các quy định của "Luật dẫn độ" và Điều ước dẫn độ thì phải chuyển "Đơn thỉnh cầu dẫn độ" và hồ sơ kèm theo lên Tòa án nhân dân tối cao, viện kiểm sát nhân dân tối cao. 
Người bị thỉnh cầu dẫn độ đã bị dẫn độ giam giữ trước khi nước ngoài thỉnh cầu dẫn độ chính thức, sau khi nhận được "Đơn thỉnh cầu dẫn độ" và hồ sơ kèm theo, tòa án nhân dân tối cao cần chuyển "Đơn thỉnh cầu dẫn độ" và hồ sơ kèm theo cho Tòa án nhân dân cấp cao liên quan để tiến hành thẩm tra; Người bị thỉnh cầu dẫn độ chưa bị dẫn độ giam giữ trước khi nước ngoài thỉnh cầu dẫn độ chính thức, sau khi nhận được "Đơn thỉnh cầu dẫn độ" và hồ sơ kèm theo, tòa án nhân dân tối cao cần thông báo cho bộ công an tìm kiếm người bị thỉnh cầu dẫn độ. Sau khi tìm được người bị thỉnh cầu dẫn độ, tùy theo tình hình mà cơ quan công an thực hiện giam giữ dẫn độ hoặc cư trú giám sát dẫn độ đối với người bị thỉnh cầu dẫn độ, và do Bộ công an thông báo với tòa án nhân dân tối cao. Sau khi nhận được thông báo của Bộ công an, tòa án nhân dân tối cao cần kịp thời chuyển "Đơn thỉnh cầu dẫn độ" và hồ sơ tài liệu kèm theo cho tòa án nhân dân cấp cao liên quan để tiến hành thẩm tra. Sau khi tìm kiếm, cơ quan công an xác nhận người bị thỉnh cầu dẫn độ không nằm trong lãnh thổ Trung Quốc hoặc không tìm thấy người bị thỉnh cầu dẫn độ, Bộ công an cần thông báo kịp thời cho tòa án nhân dân tối cao. Sau khi nhận được thông báo của Bộ công an, Tòa án nhân dân tối cao cần thông báo cho Bộ ngoại giao tình hình tìm kiếm, do Bộ ngoại giao thông báo với Nước thỉnh cầu.

Sau khi thẩm tra, Viện kiểm sát nhân dân tối cao cho rằng tội mà thỉnh cầu dẫn độ nêu ra hoặc các tội khác của người bị thỉnh cầu dẫn độ phải do cơ quan tư pháp Trung Quốc truy cứu nhưng chưa thực hiện tố tụng hình sự thì phải lần lượt thông báo các ý kiến chuẩn bi thực hiện tố tụng hình sự cho tòa án nhân dân tối cao và bộ ngoại giao trong vòng 1 tháng kể từ ngày tự nhận được Đơn thỉnh cầu dẫn độ và hồ sơ tài liệu kèm theo.

Căn cứ theo quy định về điều kiện dẫn độ của "Luật dẫn độ" và Điều ước dẫn độ, Tòa án nhân dân cấp cao tiến hành thẩm tra thỉnh cầu dẫn độ của Nước dẫn độ, do 3 thẩm phán tổ chức phiên tòa thực hiện. Tòa án nhân dân tối cao thẩm tra điều kiện dẫn độ cần nghe trần thuật của người bị thỉnh cầu dẫn độ và ý kiến của luật sư Trung Quốc họ ủy quyền, và gửi bản sao Đơn thỉnh cầu dẫn độ cho người bị thỉnh cầu dẫn độ trong vòng 10 ngày kể từ khi nhận được Đơn thỉnh cầu dẫn độ do tòa án nhân dân tối cao chuyển đến. Người bị thỉnh cầu dẫn độ phải đưa ra ý kiến trong vòng 30 ngày kể từ ngày nhận được.

Sau khi thẩm tra, tòa án nhân dẫn cấp cao cần lần lượt đưa ra các tuyên bố xét xử sau: (1) Nếu cho rằng thỉnh cầu dẫn độ của Nước thỉnh cầu phù hợp với các quy định của "Luật dẫn độ" và Điều ước dẫn độ thì phải đưa ra tuyên bố xét xử phù hợp với điều kiện dẫn độ. Nếu người bị thỉnh cầu dẫn độ thuộc trường hợp được tạm hoãn dẫn độ theo quy định của "Luật dẫn độ", cần thuyết minh rõ trong tuyên bố xét xử. Theo thỉnh cầu của Nước thỉnh cầu, trong trường hợp không ảnh hưởng đến các tố tụng khác đang thực hiện trên lãnh thổ Trung Quốc, không xâm hại lợi ích hợp pháp của bất kỳ bên thứ ba nào trên lãnh thổ Trung Quốc, có thể đồng thời đưa ra tuyên án phù hợp với điều kiện dẫn độ cùng các tuyên bố xét xử về chuyển giao tài sản liên quan đến vụ án. (2) Nếu cho rằng thỉnh cầu dẫn độ của Nước thỉnh cầu không phù hợp với các quy định của "Luật dẫn độ" và Điều ước dẫn độ thì cần đưa ra các tuyên bố không dẫn độ.

Sau khi đưa ra tuyên bố xét xử phù hợp với điều kiện dẫn độ hoặc không cho dẫn độ, Tòa án nhân dân cấp cao phải đọc tuyên bố đối với người bị thỉnh cầu dẫn độ, và chuyển Bản tuyên bố xét xử cùng hồ sơ tài liệu liên quan trình Tòa án nhân dân tối cao phúc thẩm trong vòng 7 ngày kể từ ngày tuyên bố. Nếu người bị thỉnh cầu dẫn độ không chấp thuận tuyên bố phù hợp với điều kiện dẫn độ do tòa án nhân dân cấp cao đưa $\mathrm{ra}$, người bị thỉnh cầu dẫn độ và luật sư Trung Quốc họ ủy quyền có thể đưa ra ý kiến với tòa án nhân dân tối cao trong vòng 10 ngày kể từ ngày tòa án nhân dân đọc tuyên bố với người bị thỉnh cầu dẫn độ.

Tòa án nhân dân tối cao khi phúc thẩm tuyên bố xét xử của tòa án nhân dân cấp cao cần xử lý lần lượt căn cứ theo các trường hợp dưới đây: (1) Cho rằng tuyên bố xét xử của tòa án nhân dân cấp cao phù hợp với các quy định của "Luật dẫn độ" và Điều ước dẫn độ thì phải 
phê duyệt tuyên bố xét xử của tòa án nhân dân cấp cao; (2) Nếu cho rằng tuyên bố xét xử của tòa án nhân dân cấp cao không phù hợp với các quy định của "Luật dẫn độ" và Điều ước dẫn độ thì có thể hủy bỏ phán quyết, gửi về tòa án nhân dân xét xử ban đầu thẩm tra lại, cũng có thể đưa ra phán quyết thay đổi. Sau khi tòa án nhân dân tối cao phê duyệt hoặc đưa ra phán quyết thay đổi, tòa án nhân dân tối cao cần gửi Bản tuyên bố cho Bộ ngoại giao trong vòng 7 ngày kể từ ngày đưa ra tuyên bố xét xử, đồng thời tống đạt đến người bị thỉnh cầu dẫn độ. Nếu tòa án nhân dân tối cao phê duyệt hoặc đưa ra tuyên bố không dẫn độ thì phải thông báo ngay cho cơ quan công an xóa các biện pháp cưỡng chế áp dụng đối với người bị thỉnh cầu dẫn độ.

Bộ ngoại giao sau khi nhận được tuyên bố xét xử không dẫn độ của Tòa án nhân dân tối cao cần thông báo kịp thời cho Nước thỉnh cầu; Sau khi nhận được tuyên bố xét xử phù hợp với điều kiện dẫn độ của Tòa án nhân dân tối cao, cần trình báo Quốc vụ viện quyết định có dẫn độ hay không. Nếu Quốc vụ viện quyết định không dẫn độ thì Bộ ngoại giao phải thông báo kịp thời với Nước thỉnh cầu, tòa án nhân dân cần thông báo ngay cho cơ quan công an xóa các biện pháp cưỡng chế áp dụng đối với người bị thỉnh cầu dẫn độ.

Dẫn độ do cơ quan công an thực hiện. Đối với trường hợp Quốc vụ viện quyết định dẫn độ, Bộ ngoại giao cần thông báo kịp thời cho Bộ công an, và thông báo thời gian, địa điểm, phương thức bàn giao người bị thỉnh cầu dẫn độ thỏa thuận giữa Nước thỉnh cầu và Bộ công an và các vấn đề khác liên quan đến thực hiện dẫn độ. Cơ quan công an thực hiện dẫn độ phải căn cứ theo tuyên bố xét xử của tòa án nhân dân, bàn giao tài sản liên quan đến vụ án cho Nước thỉnh cầu. Khi không thể thực hiện dẫn độ vì người bị thỉnh cầu đẫn dộ tử vong, chạy trốn hoặc vì các nguyên nhân khác, cũng có thể bàn giao cho Nước thỉnh cầu các tài sản trên. dẫn độ

Quy trình Trung Quốc thỉnh cầu nước ngoài

Trung Quốc thỉnh cầu nước ngoài cho phép dẫn độ hoặc dẫn độ quá cảnh, cần do cơ quan thẩm phán, kiểm sát, công an, an toàn quốc gia hoặc cơ quan quản lý tù của Tỉnh, Khu tự trị, thành phố trực thuộc quản lý phụ trách làm vụ án liên quan đưa văn bản ý kiến cho tòa án nhân dân tối cao, viện kiểm sá nhân dân tối cao, bộ công an, bộ an toàn quốc gia, bộ tư pháp, kèm theo hồ sơ tài liệu liên quan và bản dịch phải được công chứng, chứng thực. Tòa án nhân dân tối cao, viện kiểm sá nhân dân tối cao, bộ công an, bộ an toàn quốc gia, bộ tư pháp sẽ lần lượt thẩm tra cùng Bộ ngoại giao, sau khi đồng ý, thông qua bộ ngoại giao đưa ra thỉnh cầu đối với nước ngoài. Trong trường hợp khẩn cấp, có thể trước khi thỉnh cầu nước ngoài chính thức, thông qua con đường ngoại giao hoặc con đường khác mà nước bị thỉnh cầu đồng ý, thỉnh cầu nước ngoài áp dụng biện pháp cưỡng chế trước đối với người liên quan.

Đơn, văn bản và tài liệu cần thiết trong thỉnh cầu dẫn độ, dẫn độ quá cảnh hoặc áp dụng biện pháp cưỡng chế đều phải được đưa ra theo quy định của Điều ước dẫn độ; Nếu không có Điều ước dẫn độ hoặc Điều ước dẫn độ không có quy định, có thể tham khảo các quy định liên quan trong "Luật dẫn độ" để đưa ra; Khi Nước bị thỉnh cầu có yêu cầu đặc biệt, với điều kiện không vi phạm nguyên tắc cơ bản của luật pháp Trung Quốc, có thể đưa ra theo yêu cầu đặc biệt của Nước bị thỉnh cầu.

Đối với phê duyệt điều kiện dẫn độ đi kèm của nước bị thỉnh cầu, trong trường hợp không phương hại chủ quyền quốc gia, lợi ích quốc gia, lợi ích công cộng, có thể do Bộ ngoại giao đại diện chính phủ Trung Quốc cam kết với Nước bị thỉnh cầu. Đối với các cam kết hạn chế truy tố, do viện kiểm sát nhân dân tối cao quyết định; Đối với cam kết mức hình hạt, do tòa án nhân dân tối cao quyết định. Khi truy cứu trách nhiệm hình sự đối với người bị dẫn độ, cơ quan tư pháp phải chịu ràng buộc về các cam kết đưa ra.

Cơ quan công an chịu trách nhiệm đón nhận người bị dẫn độ về nước và các tài sản, vật dụng có liên quan của vụ án. Đối với các thỉnh cầu dẫn độ do các cơ quan khác đưa ra, cơ quan công an sau khi nhận người dẫn độ và các tài sản, vật dụng có liên quan đến vụ án, phải ngay 
lập tức chuyển giao cho cơ quan đưa ra thỉnh cầu dẫn độ; cũng có thể nhận người dẫn độ và các tài sản, vật dụng có liên quan đến vụ án cùng với các cơ quan có liên quan.
Tài liệu tham khảo

[1] 中华人民共和国刑事诉讼法[2012年修正]

[2] 中华人民共和国引渡法.

\title{
International Cooperation in the Criminal Procedure of China
}

\author{
Ngu Quang Hong \\ Guangxi University for Nationalities, No.188 Daxue E, Nanning, Guangxi, China
}

\begin{abstract}
International cooperation in criminal procedures was very early prescribed by the Chinese law. The provisions of law on international cooperation in criminal proceedings have positively contributed to the struggle and handling of crimes involving foreign elements, organized crimes and transnational crimes. These regulations also promote China's cooperation with other countries in the criminal justice field. This article introduces some basic contents of international cooperation in criminal proceedings of China and the related issues.
\end{abstract}

Keywords: People's Republic of China, criminal procedure, international cooperation in criminal procedure, extraction, judicial assistance, offender transfer 